SCIENTIFIC REPORT

\title{
National survey of antimetabolite use in glaucoma surgery in the United Kingdom
}

\author{
D Siriwardena, B Edmunds, R P L Wormald, P T Khaw
}

Br J Ophthalmol 2004;88:873-876. doi: 10.1136/bjo.2003.034256

\begin{abstract}
Aims: To assess the pattern of use of antimetabolites in trabeculectomy surgery by all consultant ophthalmologists in the United Kingdom.

Methods: A postal questionnaire of 12 questions regarding antimetabolite use in trabeculectomy surgery was sent to all 749 consultant ophthalmologists in the United Kingdom. The consultants were asked to estimate the number of trabeculectomies they performed per year, how often they used 5fluorouracil (5-FU) in primary and redo surgery, their usual method of administration of 5-FU, how often they used mitomycin $(\mathrm{MMC})$ in primary and redo surgery, and their usual dosage regimen of MMC. Factors that influenced the decision to use or not use antimetabolites were also assessed. Results: The response rate of consultants returning the questionnaire was $82 \%$ (615 out of 749); $87 \%$ (533) of these consultants perform trabeculectomy surgery. Of these 533 consultants, 98 (18\%) never use an antimetabolite. Most consultants $(82 \%)$ use antimetabolites, but use them infrequently (only $9 \%$ using antimetabolites in more than half their cases). The preferred antimetabolite is 5-FU rather than MMC. Of the 435 consultants performing trabeculectomy surgery and using antimetabolites, 402 (93\%) use 5-FU and $179(41 \%)$ use MMC. Various factors influenced the decision to use or not use an antimetabolite, but experience of complications associated with their use was a factor for $34 \%$ of consultants.

Conclusion: The use of antimetabolites, particularly MMC, in the United Kingdom is much less than in America or Japan, where trabeculectomy with $M M C$ is the surgical procedure preferred by glaucoma specialists.
\end{abstract}

$\mathrm{T}$ he wound healing response is the single most important determinant of the final intraocular pressure (IOP) after glaucoma surgery. ${ }^{12}$ The increasing use of antimetabolites to modulate this response, particularly 5-fluorouracil (5-FU) and mitomycin C (MMC), represents one of the major new developments in glaucoma surgery over the past 15 years. However, antimetabolites have been associated with particular problems and side effects, such as hypotony, bleb leaks, and infections. ${ }^{34}$ The National Trabeculectomy Survey in the United Kingdom found that in 1996 glaucoma specialists (self reported) used intraoperative antimetabolites in only $14.7 \%$ of first time trabeculectomies for chronic open angle glaucoma (COAG). ${ }^{5}$ This is in contrast with the United States, where a survey suggested that ophthalmologists with an interest in glaucoma used intraoperative MMC in 33\% to $52 \%$ of first time trabeculectomy cases. ${ }^{6}$

This National Survey of Antimetabolite Use is a cross sectional survey designed to assess in detail the pattern of antimetabolite use by all consultant ophthalmologists in the United Kingdom. There is a range of antifibrotic agents available, including 5-FU applied intraoperatively on a sponge, postoperative 5-FU injections, and intraoperative MMC. ${ }^{7-9}$ This survey investigates which of these options is preferred practice in addition to determining if antifibrotic agents are being used in first time trabeculectomy surgery as well as redo surgery.

\section{METHODS}

A postal questionnaire (see appendix) of 12 questions regarding antimetabolite use in trabeculectomy surgery was sent to all 749 consultant ophthalmologists in the United Kingdom in December 1999. They were identified according to the Royal College of Ophthalmologists database of consultants. A pilot questionnaire had previously been performed with the aid of a mixed sample of glaucoma specialists and other ophthalmologists. This was to ensure the format covered all the questions we wanted asked, was simple to answer, and the replies could be accurately interpreted. Completed questionnaires were returned to the authors in a prepaid self addressed reply envelope. Data from the paper questionnaires were entered into a customised database and analysed using Microsoft Access 2000 and SPSS (Statistical Package for Social Sciences, 1998).

\section{RESULTS}

The response rate was high, with $82 \%$ (615 out of 749) of the consultants surveyed returning the questionnaire. Data from all 615 returned questionnaires were suitable for analysis. One quarter of consultants participating in this survey reported that they had a specialist interest in glaucoma. Eighty seven per cent (533) of consultants performed trabeculectomy surgery and information from this group was used in the subsequent analyses. When asked how many trabeculectomies they performed in the past year, 35\% estimated less than 10 and $58 \%$ estimated 11 to 50 . Only $7 \%$ (35) of consultants said they performed more than 50 trabeculectomies per year.

Of all consultants performing trabeculectomy, 18\% (98/ 533) never use an antimetabolite in trabeculectomy surgery and only 9\% (49/533) used an antimetabolite in more than half of their cases (fig 1). Of those consultants with a specialist interest in glaucoma $10 \%$ never use an antimetabolite in trabeculectomy surgery, while 23\% used an antimetabolite in more than half of their cases.

Further questioning regarding first time and redo trabeculectomy surgery revealed that $25 \%$ of all consultants never use antimetabolites in primary surgery and 5\% never use antimetabolites for repeat surgery either. However, 53\% use antimetabolites in more than half their redo cases (fig 2). Those consultants who expressed a specialist interest in glaucoma were not dissimilar to the national standard: $16 \%$ of these consultants never use antimetabolites in primary

Abbreviations: COAG, chronic open angle glaucoma; 5-FU, 5fluorouracil; IOP, intraocular pressure; MMC, mitomycin $C$ 


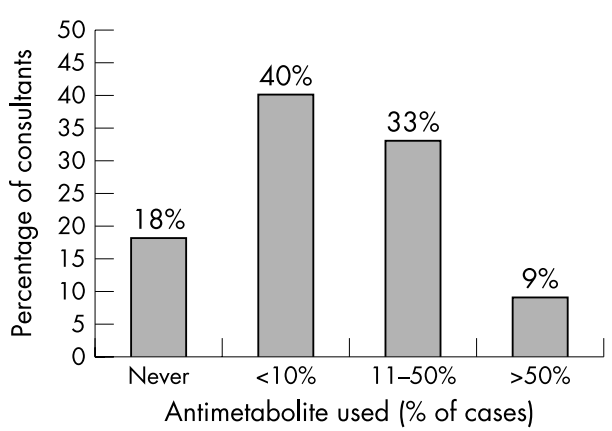

Figure 1 Frequency of antimetabolite use in trabeculectomy.

surgery, $4 \%$ never use antimetabolites for repeat surgery either, but $58 \%$ use antimetabolites in more than half of redo cases.

A total of 435 consultants participating in the survey used antimetabolites when performing trabeculectomy surgery. Data from this group were further analysed to give detailed information regarding choice of antimetabolite and method of application. Of this group, 34\% (143) use 5-FU intraoperatively on a sponge only, $6 \%$ (27) use postoperative 5-FU injections only, and 53\% (229) use both techniques. Interestingly, a small subgroup (7\% (32)) uses MMC only and no 5-FU at all (fig 3). However, the preferred antimetabolite is 5-FU rather than MMC, with 93\% (402) using 5-FU compared to $41 \%$ (179) using MMC. Of the 435 consultants performing trabeculectomy surgery with antimetabolites, 256 (59\%) never use MMC. A further 129 (30\%) consultants use MMC in less than $10 \%$ of cases. Only $37(9 \%)$ use MMC in $11-50 \%$ of cases and just 10 consultants (2\%) reported using mitomycin in more than half their cases (fig 4).

The concentration of MMC used ranged from $0.1-0.5 \mathrm{mg} /$ $\mathrm{ml}$, with $0.2 \mathrm{mg} / \mathrm{ml}$ being the most favoured dosage (fig 5). Application times ranged from less than 1 minute to more than 5 minutes, with $73 \%$ using MMC for 2-4 minutes (fig 6). Various factors influenced the decision to use or not use an antimetabolite, but experience of complications associated with their use was reported by $34 \%$ of consultants. Comparison between consultants using antimetabolites and those who never use them showed that antimetabolite users were much more likely to be influenced by recognised patient risk factors for failure such as previous topical medication $(52 \% \vee 13 \%)$, failed trabeculectomy (94\% vs $54 \%)$ and previous surgery $(63 \% v 13 \%)$ (table 1$)$.

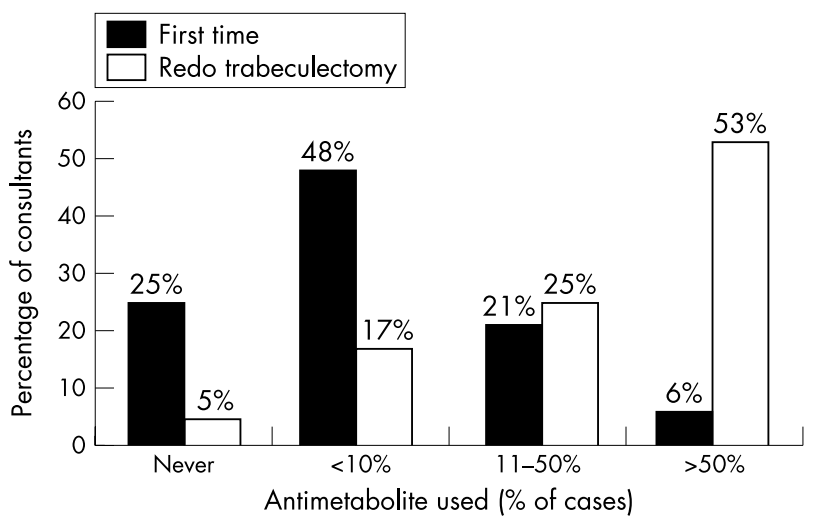

Figure 2 Frequency of antimetabolite use in first time and redo trabeculectomy.

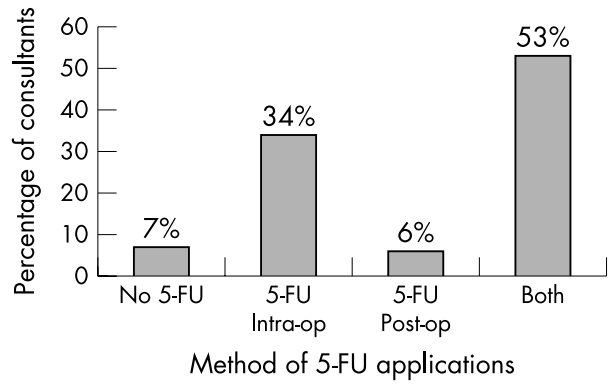

Figure 3 Technique of 5-FU administration.

\section{DISCUSSION}

This study reveals the pattern of antimetabolite use in trabeculectomy surgery in the United Kingdom. When interpreting the results of this postal survey, the issues of bias associated with sampling, recall, and non-responder rate need to be remembered. Sampling bias is limited by sending this survey to all consultants in the United Kingdom. The effect of recall bias is an important factor to consider, as we asked consultants to report on their antimetabolite use rather than measuring it directly. It is also possible that ophthalmologists with a specialist interest were more likely to respond. A high response rate in survey research increases statistical power, allows the results to be more representative of the population surveyed, and reduces (but does not eliminate) bias. This survey had a response rate of $82 \%$. A response rate of $65 \%$ and above is usually regarded as high. ${ }^{10}$

Thirty five per cent of consultants estimated that they carry out less than 10 trabeculectomies each year, which is consistent with other evidence that the amount of glaucoma surgery being performed has declined. ${ }^{11}$ Only $7 \%$ of consultants said they performed more than 50 trabeculectomies per year.

Most consultants report using antimetabolites (82\%), but they use them very infrequently, with only $9 \%$ using antimetabolites in more than half their cases. Although the actual amount of use of antimetabolites was low in this survey, the finding that $82 \%$ of consultants stated they did sometimes use antimetabolites gives a different impression from the recent UK National Survey of Trabeculectomy which found antimetabolites used in $4 \%$ to $15 \%$ of cases. ${ }^{5}$ However, there may be no discrepancy between these two findings, as this survey asked for an estimate of practice over a l year period, while the National Survey of Trabeculectomy sampled four consecutive cases per consultant. Although most consultants will use antimetabolites, they do so very infrequently and so antimetabolite use in a sample of four consecutive cases appears low. Alternatively, there may be a true difference in the findings of these two surveys because of sampling times and case mix. The National Survey of

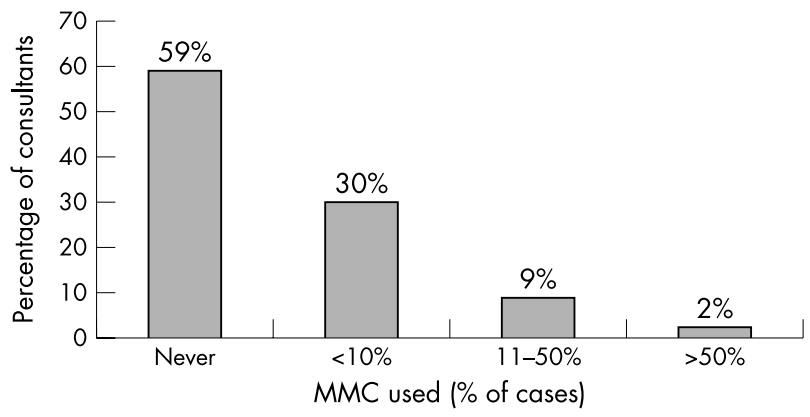

Figure 4 Frequency of MMC use in trabeculectomy. 


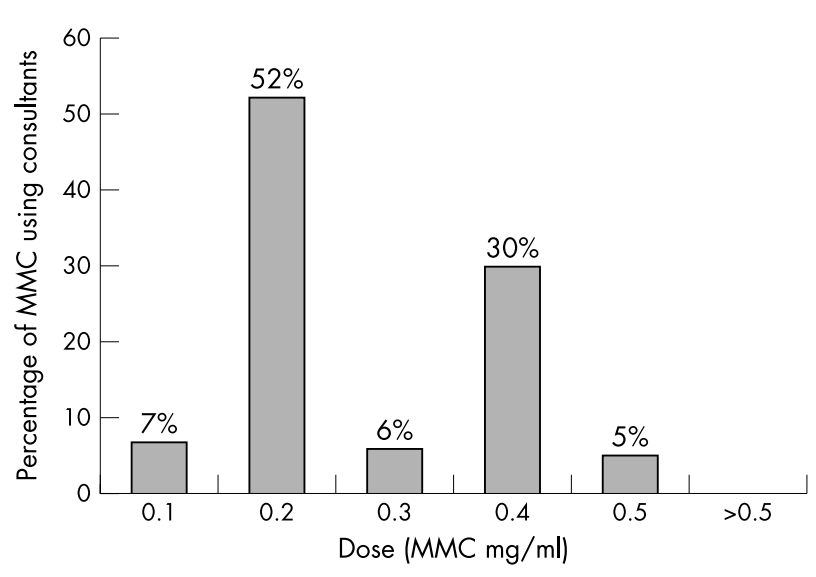

Figure 5 Concentration of MMC used.

Trabeculectomy sampled cases before June 1996, while this antimetabolite survey reflects the year up to the end of January 2000, so there may be a genuine increase in the use of antimetabolites. ${ }^{12}$ Furthermore, the National Survey of Trabeculectomy concerned patients undergoing first time trabeculectomy for COAG and excluded cases with previous surgery or secondary glaucomas, which may account for a lower frequency of antimetabolite use in comparison with this study, which covered antimetabolite use in trabeculectomy for all types of glaucoma.

In the United Kingdom, 5-FU, particularly intraoperative sponge 5-FU, appears to be the preferred antimetabolite over MMC, with $93 \%$ of antimetabolite users utilising 5-FU in some cases and only $41 \%$ choosing MMC. The use of MMC in the United Kingdom is much less than in America or Japan, where trabeculectomy with MMC is the surgical procedure preferred by glaucoma specialists. Our results show that in the United Kingdom only $2 \%$ of consultants use MMC in more than half their cases, while in the United States the use of intraoperative MMC in first time trabeculectomy ranges from $33 \%$ to $52 \%{ }^{6}$ This may reflect the risk factors for conjunctival scarring felt to be present in the predominantly white UK population or it may be simply as a result of popular practice in the United Kingdom, with the emphasis on the relative safety of 5-FU compared with MMC. ${ }^{13}$ The commonest dose for the use of MMC was $0.2 \mathrm{mg} / \mathrm{ml}$ and the commonest time of exposure was 3 minutes. Experimental studies suggest that after 3 minutes the tissue uptake of antimetabolite begins to plateau. ${ }^{14}$

This survey showed that $25 \%$ of consultants never use antimetabolites in first time surgery and only 6\% use

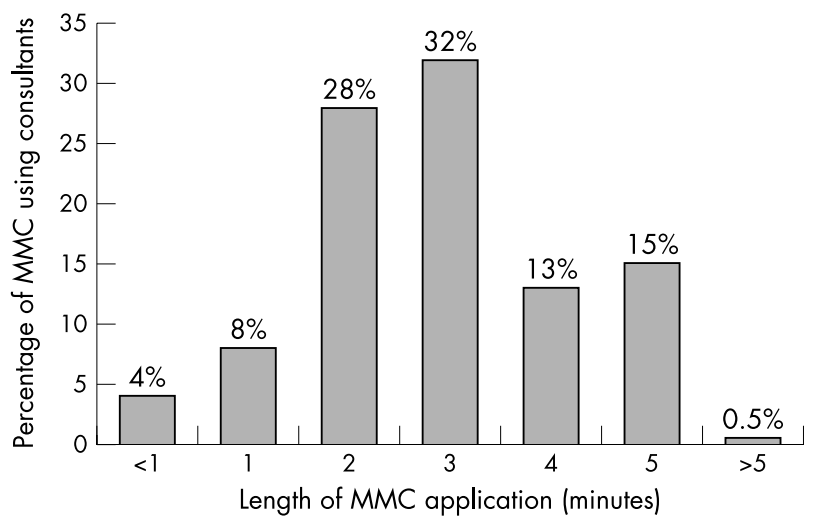

Figure 6 Time of MMC application.
Table 1 Factors influencing antimetabolite use: comparison between users and non-users

\begin{tabular}{lll}
\hline Factor & $\begin{array}{l}\text { Antimetabolite users } \\
(\%)\end{array}$ & $\begin{array}{l}\text { Antimetabolite non-users } \\
(\%)\end{array}$ \\
\hline Complications & 36 & 24 \\
Race & 88 & 48 \\
Medications & 52 & 13 \\
Trab failure & 94 & 54 \\
Previous ops & 63 & 13 \\
Uveitis & 64 & 24 \\
\hline
\end{tabular}

antimetabolites in more than half their first time surgery cases. Randomised trials have shown that 5-FU is effective in trabeculectomy surgery in east and west Africa. ${ }^{15} 16$ Interestingly, in this population MMC and 5-FU may have similar efficacy in primary surgery. ${ }^{17}$

In conclusion, this survey has given an estimate of antimetabolite use in the United Kingdom with overall frequency of use being quite low compared with America or Japan. ${ }^{6}$ As this survey was based on estimated practice in the year up to January 2000, it would be interesting to repeat this survey in the future to assess the changing pattern of antimetabolite use, particularly with the advent of new antiscarring agents. ${ }^{18}$

\section{ACKNOWLEDGEMENTS}

This work was supported in part by the Medical Research Council UK (grant G9330070, Moorfields/MRC Intraoperative 5-FU Study), Moorfields Trustees and Michael and Ilse Katz Foundation.

\section{Authors' affiliations}

D Siriwardena, R P L Wormald, P T Khaw, Institute of Ophthalmology, Bath Street, London ECIV 9EL, UK

D Siriwardena, R P L Wormald, P T Khaw, Moorfields Eye Hospital, City Road, London ECIV 2PD, UK

B Edmunds, The Princess Royal Hospital, Farnborough, Kent, UK

No proprietary interests.

Correspondence to: Dr D Siriwardena, Wound Healing and Glaucoma Research Units, Institute of Ophthalmology and Moorfields Eye Hospital, 11-43 Bath Street, London ECIV 9EL, UK; d.siriwardena@ucl.ac.uk

Accepted for publication 8 December 2003

\section{APPENDIX A: QUESTIONNAIRE}

1. Do you have a specialist interest in glaucoma?
$\square$ Yes
$\square$ No

2. Do you currently perform trabeculectomy surgery?

$$
\begin{aligned}
& \square \text { Yes } \\
& \square \text { No }
\end{aligned}
$$

If no, you do not need to answer any further questions, but please return the form.

3. Can you estimate how many trabeculectomies you performed in the year ending 31st October 1999?
$\square$ Less than 10
$\square 11$ to 50
51 to 100
$\square$ More than 100 
4. How often do you use antimetabolites in (intraop/postop) trabeculectomy cases?

\section{$\square$ Never \\ Less than $10 \%$ of cases \\ $11-50 \%$ of cases \\ More than $50 \%$ of cases}

If never, please go to question number 12 .

5. How often do you use any antimetabolite during (intraop/postop) a first time (primary) trabeculectomy?

\section{Never}

Less than $10 \%$ of cases

$11-50 \%$ of cases

More than $50 \%$ of cases

6. How often do you use any antimetabolite during (intraop/postop) a redo trabeculectomy?

Never

$\square$ Less than $10 \%$ of cases

$11-50 \%$ of cases

More than $50 \%$ of cases

7. How often do you use intraoperative 5-FU on a sponge during a trabeculectomy (first time or redo)?

\section{$\square$ Never \\ $\square$ Less than $10 \%$ of cases \\ $11-50 \%$ of cases \\ More than $50 \%$ of cases}

8. How often do you use postoperative 5-FU injections (first time or redo trabeculectomy)?

\section{Never \\ Less than $10 \%$ of cases \\ $11-50 \%$ of cases \\ More than $50 \%$ of cases}

9. How often do you use mitomycin on a sponge during a trabeculectomy (first time or redo)?

\section{Never \\ $\square$ Less than $10 \%$ of cases \\ $11-50 \%$ of cases \\ More than $50 \%$ of cases}

If never, please go to question number 12 .

10. What dose of mitomycin do you usually use? You may tick more than one box.

$\square 0.1 \mathrm{mg} / \mathrm{ml}$
$\square 0.2 \mathrm{mg} / \mathrm{ml}$
$\square 0.3 \mathrm{mg} / \mathrm{ml}$
$\square 0.4 \mathrm{mg} / \mathrm{ml}$
$\square 0.5 \mathrm{mg} / \mathrm{ml}$
$\square$ More than $0.5 \mathrm{mg} / \mathrm{ml}$

11. For how long do you usually apply mitomycin? You may tick more than one box.
$\square$ Less than 1 minute
$\square$ l minute
$\square 2$ minutes
3 minutes
4 minutes
5 minutes
Longer than 5 minutes

12. Which of the following factors influence your decision to use/not use antimetabolites? You may tick more than one box.

Patient's age

Patient's race

Patient's degree of pre-existing glaucoma damage

Patient has used topical medications

Patient has had previous failed trabeculectomy

Patient has had previous ocular surgery

Patient has history of uveitis

Patient has neovascular glaucoma

Patient has aphakic glaucoma

$\checkmark$ Personal experience of complications with antimetabolites

\section{REFERENCES}

1 Hitchings R, Grierson I. Clinicopathological correlation in eyes with failed fistulizing surgery. Trans Ophthalmol Soc UK 1983;103:84-8.

2 Addicks E, Quigley H, Green W, et al. Histologic characteristics of filtering blebs in glaucomatous eyes. Arch Ophthalmol 1983;101:795-8.

3 Stamper RL, McMenemy MG, Lieberman MF. Hypotonous maculopathy after trabeculectomy with subconjunctival 5FU. Am J Ophthalmol 1992;114:544-53.

4 Wolner B, Liebmann JM, Sassani JW, et al. Late bleb-related endophthalmitis after trabeculectomy with adjunctive 5-fluorouracil. Ophthalmology 1991;98:1053-60.

5 Edmunds B, Thompson JR, Salmon JF, et al. The National Survey of Trabeculectomy. II. Variations in operative technique and outcome. Eye 2001;15:441-8.

6 Chen PP, Yamamoto T, Sawada A, et al. Use of antifibrosis agents and glaucoma drainage devices in American and Japanese glaucoma societies. J Glaucoma 1997:6:192-6.

7 Smith MF, Sherwood MB, Doyle JW, et al. Results of intraoperative 5fluorouracil supplementation on trabeculectomy for open-angle glaucoma. Am J Ophthalmol 1992;114:737-41.

8 The Fluorouracil Filtering Surgery Study Group. Five-year follow-up of the Fluorouracil Filtering Surgery Study. Am J Ophthalmol 1996;121:349-66.

9 Chen CW, Huang HT, Bair JS, et al. Trabeculectomy with simultaneous topical application of mitomycin-C in refractory glaucoma. J Ocular Pharm 1990;6:175-82.

10 Gore-Felton C, Koopman C, Bridges E, et al. An example of maximizing survey return rates. Methodological issues for health professionals. Evaluation and the Health Professions 2002;25:152-68.

11 Whittaker KW, Gillow JT, Cunliffe IA. Is the role of trabeculectomy in glaucoma management changing? Eye 2002;15:449-52.

12 Edmunds B, Thompson JR, Salmon JF, et al. The National Survey of Trabeculectomy. I. Sample and methods. Eye 1999;13:524-30.

13 Khaw PT, Wilkins MR. In: Yanoff M, Duker JS, eds. Ophthalmology. St Louis: Mosby, 1998: Section 12. 31.1-31.7.

14 Wilkins MR, Occleston N, Kotecha A, et al. Sponge delivery variables and tissue levels of 5-fluorouracil. Br J Ophthalomol 2000;84:92-97.

15 Egbert PR, Williams AS, Singh K, et al. A prospective trial of intraoperative fluorouracil during trabeculectomy in a black population. Am J Ophthalmol 1993;116:612-16.

16 Yorston D, Khaw PT. A randomised trial of the effect of intraoperative 5-FU on the outcome of trabeculectomy in east Africa. Br J Ophthalmol 2001;85:1028-30.

17 Singh K, Egbert PR, Byrd S, et al. Trabeculectomy with intraoperative 5-fluorouracil vs mitomycin C. Am J Ophthalmol 1997;123:48-53.

18 Siriwardena D, Khaw PT, King AJ, et al. Human antitransforming growth factor beta $_{2}$ monoclonal antibody-a new modulator of wound healing in trabeculectomy: a randomized placebo controlled clinical study. Ophthalmology 2002;109:427-31. 